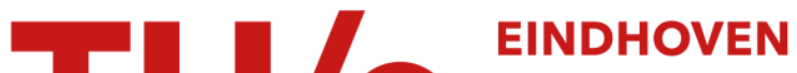 UNIVERSITY OF TECHNOLOGY
}

\section{Rapid variation with remainder and rates of convergence}

\author{
Citation for published version (APA): \\ Beirlant, J., \& Willekens, E. K. E. (1988). Rapid variation with remainder and rates of convergence. \\ (Memorandum COSOR; Vol. 8807). Technische Universiteit Eindhoven.
}

\section{Document status and date:}

Published: 01/01/1988

\section{Document Version:}

Publisher's PDF, also known as Version of Record (includes final page, issue and volume numbers)

\section{Please check the document version of this publication:}

- A submitted manuscript is the version of the article upon submission and before peer-review. There can be important differences between the submitted version and the official published version of record. People interested in the research are advised to contact the author for the final version of the publication, or visit the $\mathrm{DOI}$ to the publisher's website.

- The final author version and the galley proof are versions of the publication after peer review.

- The final published version features the final layout of the paper including the volume, issue and page numbers.

Link to publication

\section{General rights}

Copyright and moral rights for the publications made accessible in the public portal are retained by the authors and/or other copyright owners and it is a condition of accessing publications that users recognise and abide by the legal requirements associated with these rights.

- Users may download and print one copy of any publication from the public portal for the purpose of private study or research.

- You may not further distribute the material or use it for any profit-making activity or commercial gain

- You may freely distribute the URL identifying the publication in the public portal.

If the publication is distributed under the terms of Article $25 \mathrm{fa}$ of the Dutch Copyright Act, indicated by the "Taverne" license above, please follow below link for the End User Agreement:

www.tue.nl/taverne

Take down policy

If you believe that this document breaches copyright please contact us at:

openaccess@tue.nl

providing details and we will investigate your claim. 
Department of Mathematics and Computing Science

\author{
Memorandum COSOR 88-07 \\ Rapid variation with remainder \\ and rates of convergence \\ by \\ E. Beirland and E. Willekens
}

Eindhoven, Netherlands

February 1988 
Rapld variation with remainder and rates of convergence

by

$\begin{array}{ccc}\text { J. Beirlant } & \text { and } & \text { E. Willekens } \\ \begin{array}{c}\text { Katholleke Universitelt } \\ \text { Ledven }\end{array} & & \text { Technologische Unlversitelt } \\ \text { Eindhoven }\end{array}$

ABSTRACT. The remainder term of the class $\Gamma$ of rapldly varying functions is considered. Some probabilistle applications to limit laws of extreme value theory and to the estimation of the indexparameter of a regularly varying tall are consldered.

AMS Subject Classification: 26A12,60F05.

Keywords and Phrases: regular variation, rates of convergence, domains of attraction 


\section{INTRODUCTION}

Let $U: \mathbb{R} \rightarrow \mathbb{R}^{+}$be a measurable function such that

$$
\lim _{x \rightarrow \infty} U(t x) / U(x)=t^{\alpha} \text { for every } t>0 .
$$

Then U Is called regularly varying with index $\alpha\left(K K R_{\alpha}\right)$. If $\alpha=0$ we say that $U$ is slowly varying, whlle if $a=\infty U$ is called rapidly varying. An important class of rapidly varying functlons is the so-called class $T$, introduced by de Haan (1970):

let $f: \mathbb{R} \rightarrow \mathbb{R}^{+}$be a measurable function, then $f \in \Gamma$ iff there exists a measurable function $\phi: \mathbb{R} \rightarrow \mathbb{R}^{+}$such that

$$
\text { (1.1) } \lim _{x \rightarrow \infty} f(x+u \phi(x)) / f(x)=\exp (u)
$$

locally untformly (l.u.) in $u \in \mathbb{R}$.

If (1.1) holds, we call $\phi$ an auxlliary function of $f$ (notation $f \in \Gamma\{\phi\rangle)\}$ and It is known that in this case $\phi$ is self-neglecting (see de Haan (1970)\}:

$$
\lim _{x \rightarrow \infty} \phi(x+u \phi(x)) / \phi(x)=1
$$

1.u. In $u \in \mathbb{R}$.

At this point, notlce that our definition of $\Gamma$ is somewhat more general than the one glven by de Haan (1970) as he restricts the class $\Gamma$ to monotone functions which satisfy (1.1) polntwise in uER.

By far the most important probabilistic application of $\Gamma$ is the characterization of the domain of attraction of the double exponential law in the maximumscheme: let $X_{1: n} \leq X_{2: n} \leq \ldots \leq x_{n: n}$ denote the order statistics of a sample of size $n$ from a distribution function (df) $F$. We denote $F=1-F$. Then one can find rormallzing constants $a_{n}>0$ and $b_{n}$ such that for all $x \in \mathbb{R}$,

$$
\begin{aligned}
P\left(X_{n: n^{-b} n} \leq a_{n} x\right) & \rightarrow \exp (-\exp (-x))=: \wedge(x), \quad n \rightarrow \infty \\
& \text { Iff } \\
1 / F & \in \Gamma
\end{aligned}
$$


Another characterizing property of $\Gamma$ conoerns the Hill estimator (Hill(1975), Beirlant and Teugels(1987)): If $F \in C:=[F \mid F(0)=0, F$ continuous and eventually strictly increasing $]$, then Hill's estimate

$$
H_{m, n}:=m^{-1} \sum_{i=1}^{m} \log x_{n-1+1: n}-\log x_{n-m: n}
$$

Is attracted as $n \rightarrow \infty$ to the gamma law of $m^{-1} \sum_{i=1}^{m} E_{l}\left(E_{l}, l=1, \ldots, m, 11 d\right.$ exponential random variables with mean onel iff 1/Foexp $\in \Gamma$.

Both examples suggest that that we can obtain second order theorems if we could specify (1.1) up to a remainder term. We therefore consider the following asymptotic relations:

let $r$ be a measurable function from $\mathbb{R}$ to $\mathbb{R}^{+}$such that $r(x) \rightarrow 0$ as $x \rightarrow \infty$. Then

$\left(\left[R_{1}\right) \quad f(x+u \phi(x)) / f(x)=e^{u}(1+O(r(x)) \quad(x \rightarrow \infty) \quad\right.$ l.u. In $u \in \mathbb{R}$

$\left(\Gamma_{2}\right) \quad f(x+u \Phi(x)) / f(x) \sim e^{u}(1+m(u) r(x)) \quad(x \rightarrow \infty) \quad$ 1.u. $\ln u \in \mathbb{R}$

$\left(\Gamma R_{3}\right) \quad f(x+u \phi(x)) / f(x)=e^{u}(1+o(r(x)) \quad(x \rightarrow \infty) \quad$ l.u. In $u \in \mathbb{R}$.

If $f$ satisfies one of the relations $\left(\Gamma R_{1}\right)(1=1,2,3)$, with auxillary functions $\phi$ and $r$, we denote It as fE$\Gamma R_{1}(\phi, r)$.

It is well-known that $\Gamma$ is strongly connected with the class $\Pi$ of slowly varying functions (de Haan (1970)): If $f$ is non-decreasing, $f(\Gamma(\phi)$ Iff

$$
\lim _{x \rightarrow \infty}\left(f^{l}(x t)-f^{\prime}(x)\right) / \phi\left(f^{l}(x)\right)=\log (t) \quad \text { for every } t>0
$$

where $f^{\prime}$ is the inverse of $f$. We denote (1.3) as $f^{\prime} \in \Pi\left(\phi\left(f^{\prime}\right)\right)$.

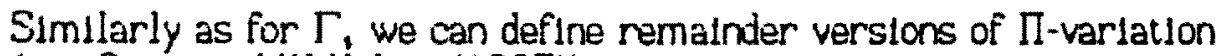
(see Diney and Willekens(1987)):

for posillve measurable functions $a$ and $b$, consider 
$\begin{array}{lll}\left(I R_{1}\right) & f(x t)-f(x)-a(x) \log (t)=O(b(x)) & (x \rightarrow \infty) \\ \left(I R_{2}\right) & f(x t)-f(x)-a(x) \log (t) \sim h(u) b(x) & (x \rightarrow \infty) \\ \left(\Pi R_{3}\right) & f(x t)-f(x)-a(x) \log (t)=o(b(x)) & (x \rightarrow \infty) .\end{array}$

Similarly as above, we use the notation $f \in R_{1}(a, b), 1=1,2,3$.

As one might expect and as was shown by de Haan and Dekkers (1987), the stated relationship between $\Gamma$ and $\Pi$ (see (1.3)) maintains (under appropr late conditions) for the remalnder versions, l.e.

$$
f \in \Gamma R_{1}(\phi, r) \text { iff } f^{l} \in \Pi R_{1}(\phi(f), \phi(f) r(f)), 1=1,2,3 \text {. }
$$

In the next section we define a transform which also relates the classes $\Gamma R_{1}$ and $\Pi R_{1}$, but which is also valid for non-monotone functions.

The analytic results of section 2 are then applied in section 3 to establish rates of convergence in the previously mentioned examples.

Before starting with section 2, we notioe that IR is closely related to the concept of slow variation with remainder (SR,) as defined in Coldte and Sinith (1987). Indeed, If $b(x) \rightarrow \infty(x \rightarrow \infty)$, we have for any function $f$ that $f \in \Pi R_{1}(0, b)$ tff expfeSR ${ }_{1}(b)$.

\section{SOME ANALYTIC RESULTS}

As in Coldie and Smith (1987) and Omey and Willekens (1987) it will be approprlate to impose some conditions on the remainder term $r$ in $\Gamma R_{1}$ $(1=1,2,3)$. Unless otherwise stated, we will assume that

$$
\lim _{x \rightarrow \infty} r(x+u \phi(x)) / r(x)=\exp (\gamma u) \text { for every } u \in \mathbb{R} \text { and some } \gamma \leq 0 \text {. }
$$

Clearly the limit tri (2.1) can only be of the stated form. In the proof of our theorems we will frequently use the following propositton, due to Bingham and Coldie (1983). 
Proposition. Let $\phi$ be self-neglecting, g satisfy

$$
(g(x+u \phi(x))-g(x)) / z(x) \rightarrow 0 \quad(x \rightarrow \infty)
$$

with $z$ a measurabie function satisfying

$$
z(x+u \phi(x)) / z(x) \rightarrow \exp (\gamma u) \quad(x \rightarrow \infty), \gamma \leq 0, u \in \mathbb{R} .
$$

Then (2.2) holds unlformly on compact u-sets.

We now define the transform which will be considered in the forthcoming theorem: suppose $\phi$ is bounded away from zero on any finite interval, and let

$$
\Phi(x):=\int_{0}^{x} d t / \phi(t), \quad x \in \mathbb{R} .
$$

Then $\Phi$ is a strictly increasing continuous function whose inverse is welldefined. Define for any $f \in \Gamma(c \phi), c \in \mathbb{R}_{0^{\prime}}$

$$
A: f \rightarrow A_{f:}=f \circ \Phi^{l} \circ \log \text {. }
$$

It follows from de Haan (1973) that any function $f$ in $\Gamma(\phi)$ can be represented as.

$$
f(x)=U(\exp \Phi(x)) \quad \text { with UER } .
$$

Clearly with the definition of $A,(2.4)$ implies that $A_{f}=U$ whence $\log A_{f} \in \Pi(1)$. So the operator $A$ provides an obvilous relation betwen $\Gamma$ and $\Pi$, and it is not hard to Imagine that we can expect a similar relation between $\Gamma R_{1}$ and $\Pi R_{1}$. Before stating the main theorem of this section, we first consider the function $\Phi$ somewhat closer.

By local uniformity in (1.2), we have for any $u \in \mathbb{R}$,

$$
\begin{aligned}
\Phi(x+\operatorname{lu\phi }(x))-\Phi(x) & =\int_{x}^{x+u \phi(x)} d t / \phi(t) \\
& =\int_{0}^{u} \phi(x) / \phi(x+v \phi(x)) d v \\
& =u+0[1) \quad(x \rightarrow(a))
\end{aligned}
$$


Conversely, flxirg any number $u \in \mathbb{R}$, one can find $t=t(x)$ with $t(x) \rightarrow u$ as $x \rightarrow \infty$ such that (cir. Bingham and Goldle (1983))

$$
\Phi(x+t(x) \phi(x))=\Phi(x)+u .
$$

This relation is very useful and will be used throughout in the sequel of the paper. We now state our matn theorem.

Theorem 2.1. Let $\phi$ be self-neglecting and let $r$ satisfy (2.1). For any $\mathrm{I} f(1,2,3\}$ the following ossertions are equivalent:

(i)

$$
f \in \Gamma R_{1}(\phi, r)
$$

Proof. We flrst prove the theorem for $1=2$.

$(i) \rightarrow(11)$. From the defintion of $A_{f}$ we have that $f(x)=A_{f}(\exp \Phi(x))$. Therefore,

$$
\begin{gathered}
f \in \Gamma R_{2}(\phi, r) \\
\text { Iff }
\end{gathered}
$$

$$
A_{f}(\exp \Phi(x+u \phi(x))) / A_{f}(\exp \Phi(x))-\exp (u)=e^{u}(u) r(x) \quad(x \rightarrow \infty)
$$

Now with $t(x)$ defined as in (2.5), It follows from local uniformity that

$$
A_{f}\left(e^{\Phi(x)+u} / A_{f}\left(e^{\Phi(x)}\right)-e^{u}-e^{u}(t(x)-u) \sim e^{u} m(u) r(x) \quad(x \rightarrow \infty)\right. \text {. }
$$

We first determine the order of $t(x)-u$. Defining

$$
R_{u}(x):=(\log f(x+u \phi(x))-\log f(x)-u) / r(x) \text {. }
$$

we have that

$$
\begin{aligned}
R_{u+v}(x)= & R_{v(x)}(x+u \phi(x)) r(x+u \phi(x)) / r(x) \\
& +R_{u}(x)+v(-1+[\phi(x) / \phi(x+u \phi(x))] / r(x)
\end{aligned}
$$


with $v(x)=v \phi(x) / \phi(x+u \phi(x))$.

Then by $\Gamma_{2}$ and $(2.1)$,

$$
\lim _{x \rightarrow \infty}(\phi(x+u \phi(x))-\phi(x)) / \phi(x) r(x) \text { exists. }
$$

Denoting the limit in (2.8) as $k(u)$, it is not hard to show that

$$
k(u)=a \int^{e^{u}} \theta^{\gamma-1} d \theta .
$$

with a a real constant and $y$ determined by (2.1).

Using Proposition one can show that convergence in (2.8) holds l.u. In $u \in \mathbb{R}$, so that

1.u. In $t \in \mathbb{R}$.

$$
\begin{aligned}
(\Phi(x+t \phi(x))-\Phi(x)-t) / r(x)=(r(x))^{-1} \int_{0}^{t}[(\phi(x) / \phi(x+u \phi(x)))-1] d u \\
\rightarrow h(t):=-\int k(u) d u .
\end{aligned}
$$

This Implies that the function $t(x)$ in $(2.5)$ is of the form

$$
t(x)=u-h(u) r(x)+o(r(x)) \quad(x \rightarrow \infty) .
$$

Then clearly from (2.6), after a change of varlables $(y=\exp \Phi(x), \lambda=0$ )

$$
\log A_{f}(y \lambda)-\log A_{f}(y)-\log \lambda \sim(m(\log \lambda)-h(\log \lambda)) A_{r}(y) \quad[y \rightarrow \infty)
$$

showing that $\log A_{f} \in \Pi R_{2}\left(1, A_{r}\right)$.

The fact that $A_{\phi} \in S R_{2}\left(A_{r}\right)$ follows immedlately from $(2.8)$, local uniformity and the definition of $t(x)$.

$(11) \Rightarrow$ (III). Obviously $\log A_{f} \in \Pi R_{2}\left(1, A_{r}\right)$ iff $\left.V(x):=\log \left(A_{f}(x)\right) / x\right) \in S R_{2}\left(A_{r}\right)$.

The representation theorem follows then Immediately.

(iii) $\Rightarrow$ (I). Immediate.

The proof of the theorem for $1=1$ or 3 follows exactly the same lines. 
Only the limit relations have to be changed in 0 - or 0 -versions.

\section{Remarks.}

1. It follows from (2.5) that $r$ satisfies (2.1) Iff $A_{r} \in R_{\gamma}$.

Clearly for proving Theorem 2.1 if $I=1 \quad(1=3)$, the assumption on $r$ in $(2.1)$ can be relaxed to $r(x+u \phi(x))=O(r(x))$ (o(r $(x))\}$ as $x \rightarrow \infty$. This then implies that $A_{r}$ is O-regularly varying (see Coldle and Smlth (1987)).

2. Theorem 2.1 implies that if $\gamma<0$ in (2.1), any function $f$ satisfylng $\Gamma R_{1}$ is essentially an exponential function. Indeed, if we consider $\Gamma_{2}$ It follows from $V E S R_{2}\left(A_{r}\right)$ and Seneta(1976) (pp. 73-74) that there exists constants $c$ and $d \neq 0$ such that

$$
V(\exp \Phi(x))=d+\operatorname{cr}(x)+o(r(x)) \quad(x \rightarrow \infty) .
$$

For the same reason, there exists constants $c_{0} \neq 0$ and $c_{1}$ such that

$$
c_{0} f \phi(x)=\exp \left(c_{1} r(x)+o(r(x))\right) \quad(x \rightarrow \infty) .
$$

from which

(2.10) $\Phi(x)=c_{2}+x c_{0}^{-1}+c_{1} c_{0}^{-1} \int_{c_{3}}^{x} r(u)(1+o(1)) d u$.

Combining (2.9) and (2.10) we have from Theorem (2.1) that

$$
\begin{gathered}
f(x)=(d+c r(x)+o(r(x))) \exp \left(c_{2}+x c_{0}^{-1}+c_{1} c_{0}^{-1} \int_{c_{3}}^{x} r(u)(1+o(f)) d u\right) \\
(x \rightarrow \infty) .
\end{gathered}
$$

3. The proof of Theorem 2.1 shows that from $\Gamma_{2}$ and (2.1)

Hence

$$
m(u+v)=m(v) \exp (\gamma u)+m(u)-a v e^{u} \theta^{\gamma-1} d \theta \quad(a \in \mathbb{R}) .
$$


(2.11) $m(u)= \begin{cases}d \gamma^{-1}(\exp (\gamma u)-1)-\alpha \gamma^{-1} \int_{0}^{u}(\exp (\gamma \psi)-1) d v(d \in \mathbb{R}) & \text { if } \gamma \neq 0 \\ c u-\alpha u^{2} / 2 & \text { if } \gamma=0 .\end{cases}$

\section{APPLICATIONS IN EXTREME VALUE THEORY}

a. Rate of convergence for maxima in domain of attraction of the double exponential distribution.

Let $X_{1: n} \leq X_{2: n} \leq \ldots \leq X_{n: n}$ be an ordered sample from a df $F$ with $1 /(-\log F) \in \Gamma(\phi)$. Take $-\log F\left(b_{n}\right) \leq n^{-1} \leq-\log F\left(b_{n}-\right)$ and let $a_{n}=\phi\left(b_{n}\right)$.

Then it is well-known that (see de Haan (1970))

$$
P\left(x_{n: n} \leq a_{n} u+b_{n}\right) \rightarrow \Lambda(u):=\exp \left(-e^{-u}\right), \quad u \in \mathbb{R} .
$$

As was mentioned in the introduction, strenghtening the condition $1 /(-\log F) \in \Gamma(\phi)$ to $1 /(-\log F) \in \Gamma R_{1}(\phi, r)$ for some $1 \in[1,2,3)$ and $r(x) \rightarrow 0$, will allow us to to study the rate of convergence in (3.1). Indeed, it is easily seen that if $f \in \Gamma R_{1}(\phi, r)$,

$$
\wedge_{n}(u):=P\left(X_{n: n} \leq a_{n} u+b_{n}\right)-\Lambda(u)=O\left(r\left(b_{n}\right) \quad(n \rightarrow \infty)\right.
$$

while if $f \in \Gamma R_{2}[\phi, r)$,

$$
\Lambda_{n}(u)=\Lambda^{\prime}(u) m(u) r\left(b_{n}\right)+o\left(r\left(b_{n}\right)\right) \quad(n \rightarrow \infty) .
$$

Whereas (3.2) and (3.3) glve polntwise rates of convergence, the main problem is to show that they hold uniformly in $u \in \mathbb{R}$.

Although many papers have been devoted to the uniform rate of convergence in (3.1). Isee e. B. Anderson (1971), Cohen (1982), Omey and Rachev (1987), Resnick (1986)), it is still an open problem to give the most general condittons that imply the right rate; nearly all of the existing results work by 
specifying the Von Mises conditions.

The contrary Is true when attraction to the Frechet or Welbull law is concerned. Indeed in these cases Smith (1982) formulated best possible conditions in terms of slow varlation with remalnder.

In the theorem below, we prove that (3.2) ((3.3)) holds uniformly in $u \in \mathbb{R}$ under $\Gamma R_{1}\left(\Gamma R_{2}\right)$. Using the theory of section 2 , we show that $\Gamma R$ can be reduced to slow variation with remalnder so that we end $\varphi$ exactly with the same problem as was tackled by Smith (1982). We belleve that the present way of proof is properly motivated from the concept of $\Gamma$-varlation with remalnder and that it generalizes the approaches used in the references mentioned above.

The only minor drawback ts the following assumption which will be used in the theorem:

$$
F^{n}\left(b_{n}-\Phi\left(b_{n}\right) \phi\left(b_{n}\right)\right)=o\left(r\left(b_{n}\right)\right) \quad(n \rightarrow \infty)
$$

Condition (3.4) holds in most instances and may not be satisfled If $\phi$ is slowly varying with a specifled remalnder term. The following lemma ensures this statement.

Lemma 3.1. If any subsequence $\left(b_{n}^{r}\right)_{n}$ of $\left(b_{n}\right)_{n}$ for which

(1)

$$
b_{n}^{\prime}-\Phi\left(b_{n}^{\prime}\right) \phi\left(b_{n}^{\prime}\right) \rightarrow \infty
$$

and

(ii)

$$
\left.\Phi\left(b_{n}^{r}\right) \Phi\left(b_{n}^{r}\right) / b_{n}^{r} \rightarrow 1 \quad(n \rightarrow \infty)\right\}
$$

satisfies $\quad F^{n}\left\{b_{n}^{\prime}-\Phi\left(b_{n}^{\prime}\right) \phi\left(b_{n}^{\prime}\right)\right]=0\left(r\left(b_{n}^{\prime}\right)\right) \quad(n \rightarrow \infty)$

then (3.4) holds in case $F$ is concentrated on an interval of the form $\left[z_{1}+\infty\right)$. Proof. In case $F$ is concentrated on Intervals of the specifled type the only subsequences we have to consider are those for which (i) holds.

If furthermore $\limsup _{n \rightarrow \infty} \Phi\left(b_{n}^{\prime}\right) \Phi\left(b_{n}^{\prime}\right) / b_{n}^{\prime}<1$ (3.4) follows from Davls and Resnlck (1986) and the fact that $A_{r}$ is 0 -regularly varying. In case the limsup equals 1 (3.4) follows from the assumptions.

The theorem reads as follows. 
Theorem 3.1. Suppose $\phi$ is self-neglecting

a. If $1 /(-\log F) \in \Gamma R_{1}(\phi, r)$ and $(3.4)$ is satisfied, and if there exist constants $x_{0}, \theta, b, c$ all positive such that

$$
b x^{-\theta} \leq A_{r}(x t) / A_{r}(x) \leq c \quad \text { for all } x \geq x_{0}, t \geq 1 \text {, }
$$

then

$$
\sup _{u \in \mathbb{R}}\left|A_{n}(u)\right|=O\left(r\left(b_{n}\right)\right\} \quad(n \rightarrow \infty) .
$$

b. If $1 /(-\log f) \in \Gamma R\left(\phi_{,} r\right)$ and $(3.4)$ is satisfied and if $A_{r} \in R_{\gamma} \gamma \leq 0$, then

$$
\hat{A}_{n}(u)=\Lambda^{\prime}(u) m(u) r\left(b_{n}\right)+o(r(b)) \quad(n \rightarrow \infty)
$$

unlformly in $u \in \mathbb{R}$. Here $m(u)$ is given as $\ln (2.11)$.

Proof. First notice that we may assume that $F$ is suported on $[z, \infty)$ for some $z \in \mathbb{R}$ Indeed, putting $Y_{l}:=\max \left(z, X_{l}\right), t=1, \ldots, n$, It is clear that for for $n$ large enough

$$
\sup _{u \in \mathbb{R}}\left|P\left(Y_{n: n} \leq a_{n} u+b_{n}\right)-P\left(X_{n: n} \leq a_{n} u+b_{n}\right)\right|=P\left(X_{n: n} \leq z\right)=o\left(r\left(b_{n}\right)\right)
$$
where the last inequality follows from the definition of $b_{n}$ and $(3.5)$.
We now estimate

$$
\Delta_{n}(x):=1-\log \left(-n \log F\left(a_{n} \log x+b\right)\right)-\log x \mid \text { for somex }>0 \text {. }
$$

Denoting $-\log F:=f$ and $\exp \Phi\left(b_{n}\right)=: \nu_{n}$, we have from $(2.5)$ and the definttion of $b_{n}$ that

$$
\begin{aligned}
\Delta_{n}(x)= & 1-\log \left(f\left(a_{n} \log x+b_{n}\right)\right)+\log f\left(b_{n}\right)-\log x+o\left(r\left(b_{n}\right)\right) \\
= & 1-\log A_{f}\left(x \exp \left(\Phi\left(b_{n}\right)+t\left(b_{n}\right)\right)\right)+\log A_{f}\left(\exp \Phi\left(b_{n}\right)\right)-\log x \\
& \left.\quad+\operatorname{or}\left(b_{n}\right)\right) \\
\leq & \left.1-\log \left(A_{f}\left(\nu_{n} x\right) / \nu_{n} x\right)+\log \left(A_{f}\left(\nu_{n}\right) / \nu_{n}\right)+\left(t\left(b_{n}\right)-\log x\right)+o\left(r\left(b_{n}\right)\right)\right)
\end{aligned}
$$


Now by Theorem 2.1, $L(x):=A_{f}(x) / x \in \mathrm{SR}_{1}\left(A_{r}\right)$ with $1=1$ or 2 depending on whether a. or b. 1s satisfied. Using the estimation in (3.6), we can copy the proofs of Theorems 1 and 2 of Smith (1982), Implying uniform convergence in (3.2) and (3.3) over the regton $u=\log x \geqslant-\log _{n}+c$, where $c$ is some constant. Hence the proof is finished if we can show that both $\wedge\left(-\log _{n}\right)$ and $F^{n}\left(-a \log _{n}+b_{n}\right)$ are $o\left(r\left(b_{n}\right)\right)$ as $n \rightarrow \infty$. Under the conditions of the theorem, $A_{r}$ is 0-regularly varying such that $\wedge\left(-\log _{n}\right)=\exp \left(-\nu_{n}\right)=0\left(A_{r}\left(\nu_{n}\right)\right)=0\left(r\left(b_{n}\right)\right)$ $(n \rightarrow \infty)$. As to $\mathrm{F}^{n}\left(-a_{n} \log _{n}+b_{n}\right)$, notice that $-a_{n} \log \nu_{n}+b_{n}=b_{n}-\Phi\left(b_{n}\right) \phi\left(b_{n}\right)$. Lemma 3.1 applies now.

b. Rate of convergence of Hill's estimate.

Beirlant and Teugels (1987) showed that if $/ /(1$ F)oexp belongs to $\Gamma$, and $F$ is continuous and strictly increasing in a nelgborfiood of $\infty$, Hill's estimate $H_{m, n}$ given in (1.2) is attracted as $n \rightarrow \infty$ to the distribution of $m^{-1} \sum_{l=1}^{m} E_{l}=: E_{m}$, $E_{l}$ being IId exponential rv's with mean one. Let now $\phi$ be the auxiliary function corresponding to $1 /$ Foexp, $l(u)=\phi\left(\log F^{i}\left(1-u^{-1}\right)\right), u \in(0,1) ; q_{n}=m / n$, and $p_{n}^{2}=m(n-m-1) /(n-1)^{3}$. Then it was also shown that $n \rightarrow \infty, m_{n} \rightarrow \infty, m_{n}=0(n)$, and (3.7a) $\left(m_{n}\right)^{1 / 2}\left(-1+\int_{0}^{\infty}\left(q_{n}+p_{n} z\right)^{-1}\left(1-F\left(e^{u l(n / m)} F^{l}\left(1-q_{n}-p_{n} z\right)\right)\right) d u\right) \rightarrow 0$ l.u. $\ln z>0$

entall that

$$
\left(m_{n}\right)^{1 / 2}\left(H_{m, n} /(n / m)-1\right) \stackrel{d}{\rightarrow} N(0,1) .
$$

If we assume that $1 / F$ oexp $\in \Gamma R_{1}(\phi, r)$ then It is clear that condition (3.7a) can be replaced by the more attractive condition 
(3.7b) $\left(m_{n}\right)^{1 / 2} r\left(\log F^{l}\left(1-q_{n}-p_{n} 2\right)\right) \rightarrow 0$ as $n \rightarrow \infty, m_{n} \rightarrow \infty, m_{n}=0(n)$ 1.u. $\ln z>0$.

With the help of the Berry-Esseen theorem

$$
\begin{aligned}
& \sup _{x}\left|P\left(\left(m_{n}\right)^{1 / 2}\left(H_{m, n} /(n / m)-1\right) \leq x\right)-\Phi(x)\right| \\
& \leq \tau_{n}+C m^{-1 / 2}
\end{aligned}
$$

where $\tau_{n}=\sup _{x} \mid P\left(\left(m_{n}\right)^{1 / 2}\left(H_{m, n} / l(n / m)-1\right) \leq x\right)$

$$
\text { - } P\left(\left(m_{h}\right)^{1 / 2}\left(E_{m}-1\right) \leq x\right) 1 \text {. }
$$

To bound $\tau_{n}$ we apply the well known smoothing inequality:

$$
\tau_{n} \leq \pi^{-1} \int_{-T}^{T} t^{-1}\left|\psi_{m, n}(t)-k_{m}(t)\right| d t+K T^{-1} \text {. }
$$

where $\psi_{m, n}$, resp. $k_{m}$, denote the characteristic functions of the standardized versions of $H_{m, n}$, resp. $E_{m}$, given in Beirlant and Teugels (1987).

We get by choosing $T=m^{1 / 2}$ that

$$
\begin{aligned}
& \tau_{n} \leq k m^{-1 / 2} \\
& +A(n, m) \pi^{-1}(m l)^{-1} \int_{-m / n}^{m_{n} / 2} t^{-1} d t \int_{0}^{n}(1-v / n)^{n-m-1} m \\
& 1 k_{n}^{m}\left(w, m^{\left.\frac{1}{2} / t i n / m\right)}\right. \\
& -\left(1+1 \int^{\alpha} e^{\left[w-\left(w m^{\frac{1}{2}} / t\right)\right.} d w\right\} m_{1} d v \\
& 0
\end{aligned}
$$

where $A(n, m)=O(1)$ as $n \rightarrow \infty, m=O(n)$ and 


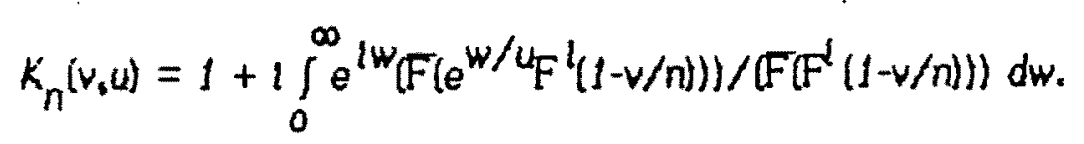

First

$$
\max \left[\mid K_{n}\left[\left(v_{1} u / l(n / m)\right)|,|\left(1+1 \int_{0}^{\infty} e^{\left(w-w / u_{d}\right.} d\right) \mid\right\} \leq 1\right.
$$

and If $1 /$ Foexp satisfles $\left(\Gamma R_{1}\right)$ we get as $n \rightarrow \infty$

$$
\mid K_{h}(v, u / l(n / m))-\left(1+1 \int_{0}^{\infty} e^{2 w-w / u} d w \mid \leq e^{-w / u} O\left(r\left(\log F^{l}[1-w / n)\right)\right)\right.
$$

so that by substituting $t / \mathrm{m}^{1 / 2}$ by $a$ we find

$$
\begin{aligned}
\tau_{n} \leq K m^{-1 / 2}+L m \int_{-1}^{1} d u \int_{0}^{n}(m I)^{-1}(1-v / n)^{n-m-1} v^{m} \\
\quad \times\left|O\left(r\left(\log F^{l}(1-v / n)\right)\right)\right| d v
\end{aligned}
$$

for a certain constant $L$.

So we have derived the following theorem.

Thearem 3.2. Suppose $F$ is continuous and strictly increasing in a neighborhood of $\infty$. Moreover assume that $1 /$ Foexp $\in \Gamma R_{1}(\phi, r)$ and that (3.16) holds.

Then there exists a positive constant $C$ such that

$$
\begin{aligned}
& \sup _{x \in \mathbb{R}}\left|P\left(m^{1 / 2}\left(H_{m, n} / l(n / m)-1\right) \leq x\right)-\Phi(x)\right| \\
& \leq C\left[m^{-1 / 2}+m E\left(\psi_{m, n, F}\left(m n^{-1} E_{m+1}\right)\right)\right\}
\end{aligned}
$$

as $n \rightarrow \infty, m_{n} \rightarrow \infty, m_{n}=0(n)$, where $\Psi_{m, n}, F^{(x)}=O\left(r \circ \log ^{2} F^{i}\left(1-x^{-1}\right)\right)$ as $x \rightarrow \infty$.

The above result generalizes results of Falk (1985), who derives rates of convergence for $H_{m, n}$ in more specific models. 
References.

Anderson C.W. (1971). Contributions to the asymptotic theory of extreme values. Ph. D; Thesis, University of London.

Beirlant J. and Teugels J.L. (1987). Asymptotics of Hill's estimator. Th. Probablitty Appl. 31, 463-469.

Bingham N.H. and Goldle C.M. (1983). On one-sided Tauberian theorems. Analysis 3,159-188.

Bingham N.H., Goldie C.M. and Teugels J.L. (1987). Regular Vartation. Encyclopedia of Math. and its Applic. 27, Cambridge Unlversity Press

Cohen J.P. (1982). Convergence rates for the ultimate and penultimate aporoximations in extreme-value theory. Adv. Appl. Prob. 14, 833854.

[avis R. and Fiesnlck S.I. (1980). Extremes of movirg averages of random varlables from the double exponential distribution. Teothical Report, Colorado State University.

De Haan L. (1970). On regular vartation and Its application to the waak convergence of sample extremes. Math. Centre Tract 32, Amsterdam.

De Haan L. (1974). Equivalence classes of regularly varylng functions. Stoch. Proc. Appl. 2, 243-259.

[e Haan L. and Dekkers A. (1988). On a consistent estimate to the Index of an extreme value distribution. To appear Ann. Probabillty.

Falk M. (1985). Uniform convergence of extreme order statistics. Habilitationsthesis, University of Slegen.

Goldie C.M. and Smith R.L. (1987). Slow varlation with remalnder: theory and applications. Quarterly J. Math. Oxford 38,45-71.

Hill B.M. (1975). A simple general approach to inference about the tall of a a distribution. Arm. Statist. 3,1163-1174.

Omey E. and Willekens $E$. (1987). $\pi$-varlation with remainder. To appear Joumal London Math. Soc..

Omey E. and Rachev S. (1987). On the rate of convergence in extreme value theory. To appear Th. Prob. Appl.

Relss R.D. (1987). Estimating the tall index of the clalm size distribution. Biatter DCVM 1,21-25.

Resnick S.I. (1986). Uniform rates of convergence to extreme value distributlons. J. Srlvastava (ed.) Probability and Statisties: Essays in honor of F.A. Graybill, N. Holland, Amsterdam.

Seneta E. (1974). Regularly varying functions. Lecture Notes in Mathematics Sús. Springer Verlag, Eerlin.

Smith R.L. (1982). Uniform rates of convergence in extreme-value theory. Adv. Appl. Prob. 14, 600-622. 